\title{
Avaliação clínico-neuro-psicológica de trabalhadores expostos a mercúrio metálico em indústria de lâmpadas elétricas
}

\author{
Neuro-psychological clinical assessment of workers in an electric lamp \\ factory exposed to metallic mercury
}

\section{Cecilla Zavariz*, Débora Miriam Raab Glina**}

ZAVARIZ, C. \& GLINA, D.M.R. Avaliação clínico-neuro-psicológica de trabalhadores expostos a mercúrio metálico em indústria de lâmpadas elétricas. Rev. Saúde públ., S.Paulo, 26:356 $-65,1992$. Objetivou-se estudar a intoxicação por mercúrio metálico em trabalhadores de uma indústria de lâmpadas elétricas no Estado de São Paulo, Brasil. Foram investigados 71 trabalhadores, dos quais $61(85,92 \%)$ apresentaram quadro de intoxicação crônica por mercúrio. 0 tempo de exposição dos trabalhadores estudados variou de 4 meses a 30 anos. Dentre os intoxicados foram detectadas alteraçōes de coordenação motora em $57(80,30 \%)$, neurológicas, em $56(78,88 \%)$, de memória, em $51(71,83 \%)$, no exame clínico, em $47(66,20 \%)$, psiquiátricas, em $45(63,38 \%)$ e da atenção concentrada, em $37(52,10 \%)$.

Descritores: Intoxicação por mercúrio, epidemiologia. Doenças ocupacionais, induzido quimicamente.

\section{1 - Introdução}

O mercúrio é utilizado em um grande número de processos industriais, entre os quais, a produçấo de lâmpadas fluorescentes ${ }^{7,15}$.

De acordo com a temperatura, a concentração de mercúrio metálico no ar se altera. A $0^{\circ} \mathrm{C}$ de temperatura a concentração de $\mathrm{Hg}$ no ar é de $2,18 \mathrm{MCG} / \mathrm{m}^{3}$, a $30^{\circ} \mathrm{C}$ a concentração é de $29,500 \mathrm{MCG} / \mathrm{m}^{3}$ e a $40^{\circ} \mathrm{C}$ é de 62,600 $\mathrm{MCG} / \mathrm{m}^{3}$.

A absorção do vapor de mercúrio metálico dá-se principalmente por via pulmonar, através da inalação. A percentagem de retenção nos pulmões varia de 74 a $76 \%$ a uma concentração ambiental de $100 \mathrm{mg} / \mathrm{m}^{3}$.

Dos pulmões o mercúrio é levado pelo sangue e se distribui no organismo, acumulando-se nos rins, sistema nervoso central, fígado, medula óssea, vias aéreas superiores, parede intestinal, pele, glândulas salivares, coração, músculos e placenta ${ }^{5,7,15}$.

* Centro de Referência em Saúde do Trabalhador de Santo Amaro da Prefeitura do Municipio de São Paulo; Divisão de Segurança e Saúde do Trabalhador do Instituto Nacional de Seguridade Social de São Paulo (INSS) - São Paulo, SP-Brasil.

** Centro de Referência em Saúde do Trabalhador de Santo Amaro da Prefeitura do Município de São Paulo e Professora - São Paulo, SP - Brasil.

Separataş/Reprints: C.Zavariz - Rua Alves Guimarāes, 485 Ap. 43 - 05410-000 - Sảo Paulo, SP - Brasil

Publicação financiada pela FAPESP. Processo Saúde Coletiva 91/4994-0
Os efeitos do mercúrio no organismo manifestam-se sob a forma de um quadro agudo, quando inalado em grande quantidade, no qual podem ocorrer lesōes pulmonares, renais, do sistema nervoso central, podendo ocasionar inclusive a morte ${ }^{5}$.

A intoxicação crônica afeta basicamente o aparelho gastrointestinal, sistema nervoso e psíquico, cujas alterações variam de quadros leves a muito graves ${ }^{11,15}$.

O quadro gastrointestinal manifesta-se por lesōes orais, de estômago, intestino e fígado. A gengivite é o distúrbio mais comumente encontrado. Também ocorrem queixas de desagradável gosto amargo ou metálico na boca, sialorréia, ulcerações orais e amolecimento de dentes. Faringite inespecífica é comum. Outra manifestação encontrada é a gastrite e gastroduodenite ${ }^{3}$.

O quadro neurológico pode manifestar-se por tremores, alterações de sensibilidade dolorosa, térmica e tátil, alteração de reflexos, coordenação motora $e$ até parkinsonismo ${ }^{3,15}$.

$O$ quadro psíquico constitui-se em constelação de alterações de personalidade que Foá e Caimi ${ }^{4}$ denominam de eretismo psíquico, referindo que os sinais típicos e precoces da intoxicação crônica por mercúrio são a irritabilidade, alteração da sociabilidade, insônia, estado de ansiedade, timidez, labilidade emocional e, nos casos mais graves, ocorre a diminuição da atenção, memória, até um processo de despersonalização geral. 
Angotzi e col. ${ }^{2}$ encontraram diferenças significativas entre o grupo experimental (exposto) e o grupo contole, em relação à força do ego, mecanismos esquizóides, nível de controle racional, de ansiedade e de tensão nervosa, justamente os fatores que mostram o equilíbrio sócio-emotivo do individuo.

Vroom e Greer ${ }^{13}$ encontraram, em seu estudo com pacientes expostos a mercúrio metálico, dados sobre ansiedade, depressão, em todos os casos, além de insônia, irritabilidade, esquecimento, dificuldade de concentração, insegurança, diminuição das habilidades sociais.

Piikivi e col. ${ }^{12}$, além dos itens anteriormente mencionados, encontraram redução da autoconfiança.

Para Alonso F. ${ }^{1}$, as psicoses exotóxicas (produzidas por agentes tóxicos, não originados no organismo) podem distribuir-se em psicosíndromes de transição (sem alteração de consciência), sindromes com alteração de consciência, desestruturação da personalidade e a psicosíndrome orgânica.

As primeiras alteraçōes psíquicas, que aparecem nas intoxicações crônicas, integram uma síndrome neurasteniforme, cujos elementos mais significativos são a astenia e a irritabilidade, além de cefaléias, vertigens, diminuição da memória, entre outros.

Caso persista a exposição ao tóxico, o quadro evolui para uma psicosíndrome orgânica. Às vezes tal síndrome manifesta-se por uma perda de iniciativa e de espontaneidade, e difículdades de lidar com situaçōes que transcendam o imediato e cotidiano.

A neuropsicologia toxicológica segundo Hartman aplica métodos de testagem neuropsicológica para assessar as disfunções cerebrais sutis, mas definidas, produzidas por substâncias neurotóxicas, apontando vantagens e desvantagens destes métodos.

As principais dificuldades apontadas foram:

a) Lidar com déficits pré-existentes, ou seja, normalmente são selecionados para cargos que não exigem qualificação profissional e, que geralmente envolvem exposiçōes a riscos, individuos cujo nível de escolaridade é baixo, o que pode camuflar deficiências intelectuais anteriores à exposição. Deve ser feita uma pesquisa nesse sentido, para facilitar a interpretação dos testes.

b) As normas da maioria dos testes neuropsicológicos não são feitas especificamente para trabalhadores expostos a riscos neurotóxicos, e sim, para a população em geral. c) A dificuldade de um diagnóstico diferencial com outras entidades mórbidas, dada a natureza global do ser humano.

As principais vantagens apontadas foram: a) A possibilidade de um diagnóstico precoce de efeitos neurotóxicos, que de outra forma não seriam detectados, já que os indivíduos podem desenvolver estratégias compensatórias alternativas para os déficits neuropsicológicos. Como os testes exigem mais e podem isolar os componentes da cognição e comportamento, efeitos compensatórios podem ser minimizados e dificuldades específicas podem ser mensuradas.

b) Os testes neuropsicológicos são seguros e não-invasivos. Não há riscos nem dor para o paciente. Podem ser repetidos para fornecer dados longitudinais sem ocasionar danos ao paciente.

c) A capacidade dos testes de avaliar uma grande variedade de funçōes corticais e subcorticais. Eles podem ser empregados para avaliar anormalidades cerebrais globais e locais. Existem diversas opções de testes para tanto.

d) Os testes neuropsicológicos são confiáveis, podendo ser reproduzidos no mesmo indivíduo ou população de pacientes. A padronização de variáveis do paciente, administração do teste, conteúdo e avaliação do teste, permite reprodução dos estudos por parte de outros pesquisadores.

e) Os custos são pequenos e não há exigência de aplicação sofísticada, ou cara, sendo necessários, apenas o material, o pesquisador e ambiente adequado.

f) Uma bateria de testes neuropsicológicos completa para avaliação de efeitos neurotóxicos pode ser facilmente transportada.

g) A avaliação neuropsicológica pode fornecer informações complementares para as avaliações médicas convencionais, inclusive com quantificaçōes.

h) Dada a sensibilidade dos métodos neuropsicológicos em detectar disfunções neurotóxicas muito iniciais, a testagem precoce pode prevenir danos cerebrais mais permanentes. Pode também identificar trabalhadores que apresentam danos devidos à exposição e sugerir a transferência para locais ou empregos distantes da exposição.

$O$ autor salienta a importância de se montar uma bateria de testes com solidez psicométrica e bem validada e de se escolher testes que enfatizem áreas de funcionamento neuropsicológico correlacionadas com as alteraçōes 
provocadas pelo agente tóxico. A bateria deve compreender uma grande gama de funções cognitivas, afetivas e neurocomportamentais.

$O$ autor, após rever as recomendaçōes de testes de vários neuropsicólogos, percebe a existência de sugestões comuns a todos. Medidas de velocidade motora, coordenação motora fina, destreza manual, memória, eficiência cognitiva, são sugeridas por todos. Como as habilidades não verbais tendem a ser as mais afetadas pelos neurotóxicos, a bateria deve enfatizar tais funçōes. Algumas baterias, mas não todas, incluem testes de personalidade como parte do exame.

Williamson e col. ${ }^{14}$ usaram um teste para medir a coordenação mão/olho ("Lafayette rotary pursuit"), um teste para medir a memória de curto prazo ("paired-associates"), um para medir a rapidez de reação ("reaction time"), um para medir memória de longo prazo (continuação do paired-associates ), entre outros. Encontraram déficits de coordenação motora ocasionados pela fadiga e tremor. Segundo os citados autores, a exposição a baixos níveis de mercúrio prejudica significativamente os processos mentais. As pessoas estudadas tiveram dificuldade em aprender as associações entre simples palavras e lembrá-las. Sendo, portanto, aparentes as dificuldades em nível de memória de curto prazo. Os citados autores não encontraram relação entre o mercúrio urinário e os déficits de desempenho psicológico, concluindo que a quantidade de metcúrio na urina não fornece um índice acurado da concentração do mercúrio no cérebro.

Piikivi e col. ${ }^{12}$ usaram um teste de inteligência verbal ("Similarities-Wechsler Adult Inteligence Scale"), um teste de memória lógica e reprodução visual ("Wechsler Memory Scale"), e um para coordenação olho-mão (Santa Ana Dexterity Test ). Encontraram os resultados mais significativos de déficits em relação à inteligência verbal e à memória.

Hanninen ${ }^{8}$ concluiu que as anormalidades neuropsicológicas induzidas por mercúrio compunham 3 grandes grupos: 1) anormalidades no sistema motor (Ex.tremor fino); 2) danos intelectuais (deterioração gradual e progressiva da memória, concentração e raciocíonio lógico); 3) dificuldades emocionais.

Angotzi e col. ${ }^{2}$ utilizaram para avaliação, entre outros: aparelho gastrointestinal - anamnese, exame clínico de cavidade oral e exames laboratoriais (bilirrubinas, transaminases, proteínas totais e eletroforese de proteínas séricas); aparelho cardiovascular - anamnese (questionário específico para doenças cardiovasculares), exame físico (auscuta cardíaca e determinação da pressão arterial, dosagem de colesterol e trigliceridios e eletrocardiograma; o aparelho urinário-dosagem de proteinuria total; aparelho otoneurológico - anamnese, exame audiométrico tonal e vocal, impedanciometria e eletronistagmografia; aparelho visual.

A eliminação do mercúrio do organismo é feita principalmente através dos rins, mas também pode ocorrer através da pele e saliva, fezes ${ }^{6}$.

Atualmente é aceito que o mercúrio urinário não é um indicador confiável de dose interna. Existe uma variabilidade individual significativa em grupos ocupacionais expostos. A correlação entre a exposição diária (avaliada na concentração do mercúrio ambiental) e o mercúrio na urina (e também no sangue), no mesmo dia, é muito pobre e em alguns casos inexistente, o que prova que a concentração na urina, assim como no sangue, no fim da jornada de trabalho, não reflete a exposição que ocorreu naquele dia.

Langolf e col. ${ }^{10} \mathrm{em}$ estudo efetuado, verificaram correlação pobre entre nivel de mercúrio urinário e incidência de sinais e sintomas em trabalhadores expostos a mercúrio elementar.

\section{2 - Material e Método}

Foi realizado um estudo transversal, compreendendo 2 aspectos:

\section{1 - Visitas à fábrica}

Realizadas a partir de agosto de 1990 para estudar o processo de trabalho. Foi verificado o fluxograma de trabalho, a jornada de trabalho, as avaliações ambientais e médicas feitas pela empresa, a relação de trabalhadores e suas respectivas funçōes e as plantas da empresa.

\section{2 - Atendimento aos trabalhadores}

Do total de 641 trabalhadores da empresa, devido a dificuldades operacionais de liberação dos trabalhadores para a realização dos exames, 71 tiveram suas avaliações concluídas até a elaboração da presente pesquisa.

Os trabalhadores foram submetidos às seguintes avaliações no período de outubro de 1990 a outubro de 1991: 


\subsection{1 - Avaliação clínica}

Foi elaborada uma ficha/prontuário para coleta de dados e anotação da propedêutica, onde constava: identificação do paciente, história ocupacional anterior, histórico de afastamentos do trabalho por acidentes ou doenças ocupacionais, anamnese ocupacional atual, descrição da função, interrogatório sobre os diversos aparelhos (gastrointestinal, cardiocirculatório, respiratório, renal, neurológico, psíquico, dérmico, visual e auditivo), indagação sobre consumo de medicamentos, bebidas alcoólicas, outras drogas, tabagismo, anotações sobre o exame físico completo. Foi feita uma primeira avaliação da escrita do paciente.

Os exames complementares solicitados foram:

a) aparelho renal: urina I, uréia e creatinina (para todos os trabalhadores)

b) aparelho gastrointestinal: exame de fezes, transaminase glutâmica oxalacética (TGO) e transaminase glutâmica pirúvica (TGP) (para todos os trabalhadores). Fosfatase alcalina e endoscopia (para alguns trabalhadores, quando necessário).

c) aparelho cardicirculatório: colesterol (para todos os trabalhadores que apresentaram hipertensão arterial).

d) sistema hematopoiético: hemograma (para todos os trabalhadores).

e) aparelho auditivo: audiometria.

\subsection{2 - Avaliação Neurológica}

A avaliação neurológica consistiu de: deteç̧ão de alterações de coordenação motora, de sensibilidade térmica, dolorosa e táctil, de reflexos, de movimentos involuntários, de força muscular, de equilíbrio, de voz, de articulação das palavtas, de pares craneanos.

\subsection{3 - Avaliaçāo Psiquiátrica}

A avaliação contituiu-se de entrevista utilizando formulário que visava detectar sintomas relacionados ao quadro de eretismo psíquico e que permitiam o estabelecimento de um diagnóstico diferencial em relação a outras patologias psiquiátricas.

* Tratam-se dos mesmos testes previstos na Resolução SS 307 de 14.8.91, publicada no Diário Oficial do Estado, seção I, em 15.8.91.

\subsection{4 - Avaliação Psicológica}

$\mathrm{Na}$ avaliação psicológica, além da entrevista inicial, foram aplicados os seguintes testes neuropsicológicos*:

- Wechsler Memory Scale (D. Wechsler e C. T. Stone), forma 1, traduzida e adaptada para o português. Os itens utilizados foram: Informação, Orientação, Controle Mental, Memória Lógica, Dígitos (ordem direta e ordem inversa), Reprodução visual e Aprendizagem por Associação. Tal teste mede a memória imediata, recente e remota; alguns itens exigem também atenção. Existe uma correção para idade. O teste fornece o Quociente de Memória (QM), cuja classificação adotada é: - QM abaixo de 50 - indica distúrbio severo de memória

. QM de 50 a 79 - indica dificuldade moderada (abaixo da média inferior)

- QM de 80 a 89 - indica dificuldade leve (média inferior)

- QM de 90 a 109 - indica normalidade (média) . QM 110 e mais - indica memória acima da média.

- Teste de Aptidão à Mecânica de L.Walther subteste de habilidade manual. Os itens utilizados foram: discos (Walther), contas (Descocudres), pontilhagem (Binet e Vaschid), percussão (M. Whitley) e recortes (Claparéde). A finalidade do teste é mensurar a rapidez dos movimentos, a destreza manual, a coordenação motora fina, a metodização e sistematização ao realizar um trabalho. As normas deste foram feitas com trabalhadores industriais. A classificação é a seguinte:

- abaixo de P19 - indica dificuldade grave

. de P20 a P30 - indica dificuldade moderada - de P31 a P49 - indica dificuldade leve

- P50 - indica normalidade (média)

- acima de P50 - superior

- Bateria Fatorial CEPA - teste de atenção concentrada de Toulouse Pieron. Mede a rapidez gráfica e motora na execução de tarefa simples, de natureza perceptiva e a exatidão com que a tarefa é realizada.

Fornece, portanto, duas medidas, $\mathrm{R}$ e $\mathrm{Q}$, ambas em percentil, sendo a classificação a seguinte:

- abaixo de P19 - indica dificuldade grave

- de P20 a P30 - indica dificuldade moderada

. de P31 a P49 - indica dificuldade leve

- P50 - indica normalidade (média)

- acima de P50 - superior.

Com os resultados das avaliações anteriormente citadas, cada caso foi discutido 
para estabelecimento de diagnóstico. Não foi considerada para fins diagnósticos nenhuma avaliação isoladamente.

\section{3 - Resultados e Discussão}

\subsection{Visita à fábrica}

A empresa em questão contava na época com 641 trabalhadores, sendo 434 homens, 190 mulheres e 16 menores, perfazendo um total de 598 na produção e 43 na administração.

A produção fica situada em um galpão industrial, edificado com estrutura metálica (telhado) e concreto armado (pilares), com paredes de alvenaria e telhas de fibrocimento. $O$ piso é de cimento com acabamento liso. A iluminação artificial é feita à base de luminárias fluorescentes.

Internamente as linhas de produção delimitam os setores, sendo circundadas por corredores de circulação que desembocam nas principais saídas da fábrica.

Dos 598 trabalhadores da produção, 192 trabalham no setor de produção de lâmpadas fluorescentes, no qual existem 2 linhas de produção de lâmpadas fluorescentes. Em cada linha há uma máquina denominada exaustão, onde cerca de $800 \mathrm{cc}$ de mercúrio metálico são distribuidos nas 48 bocas, ou dosadores. São consumidos em média $83 \mathrm{Kg}$ de mercúrio por mês. A carga completa de mercúrio é consumida em 2 dias, sendo os dosadores recarregados pelos próprios trabalhadores. O mercúrio é injetado através desses dosadores nos tubos de vácuo das lâmpadas.

$\mathrm{Na}$ empresa em estudo o mercúrio metálico só é utilizado na fabricação de lâmpadas fluorescentes. Foram observados os seguintes riscos no respectivo setor: ruído, calor, acidentes com partes móveis de máquinas, acidentes por corte com vidro, queimaduras por vidro quente, lesōes por esforços repetitivos, intoxicação por mercúrio metálico e intoxicação por chumbo.

Os riscos detectados em outros setores não foram aqui mencionados por fugirem do objetivo do presente trabalho.

Foram observadas na área de produção lâmpadas quebradas (com conseqüiente liberação de mercúrio na atmosfera, após o recebimento do mesmo na máquina denominada exaustão), presença de gotas de mercúrio no chão e em máquinas, exaustão precária, mangueiras de ventilação soltas, máquinas do setor de fluorescente com 12 a 20 anos de uso, calor em toda a área favorecendo a rápida evaporação do mercúrio, laboratório em precárias condições, falta de filtros nas saídas de exaustāo lançando mercúrio no meio ambiente, reutilização dos tubos de lâmpadas parcialmente quebradas e contaminadas por mercúrio. Houve informação de que são produzidas, em média, 10.000 lâmpadas por dia, com quebra de aproximadamente $10 \%$ deste total.

A limpeza do chão, das máquinas e peças era realizada pelos próprios trabalhadores da produção e mecânicos. Na própria área era feita a quebra das lâmpadas que apresentavam defeitos, dentro de um recipiente seco (tonel com capacidade para aproximadamente $10 \mathrm{li}$ tros).

A avaliação ambiental realizada pela empresa mostrou:

a) calor variando de 17,00 a 30,95 IBUTG;

b) mercúrio ambiental $0,00 \mathrm{mg} / \mathrm{m}^{3}$ ou traços idosáveis.

As avaliações efetuadas não mencionavam a metodologia utilizada, aparelho, local, horátio de duração da medição.

De acordo com parecer técnico da Fundacentro, * do ponto de vista químico e analítico e da significância para avaliar os niveis de exposição ocupacional ao mercúrio, os dados apresentados não têm validade.

Durante o periodo em que se realizaram as visitas não foram feitas mudanças ambientais.

\section{2 - Avaliaçāo dos trabalhadores}

Os trabalhadores avaliados eram todos do sexo masculino, não havendo nenhum analfabeto (Tabela 1). As idades variaram de 20 a 65 anos, sendo que $48(67,6 \%)$ se situavam na faixa de 20 a 35 anos. Destes, $41(57,7 \%)$ estavam intoxicados (Tabela 2).

Tabela 1. Distribuição do $n^{2}$ e \% de trabalhadores expostos a mercúrio metálico segundo nivel de instrução. Indústria de lâmpadas elétricas no Estado de São Pau. 10, 1991.

\begin{tabular}{lcc}
\hline Nível de Instrução & $N^{2}$ & $\%$ \\
\hline Analfabeto & - & - \\
Primeiro grau incompleto & 40 & 56,3 \\
Primeiro grau completo & 18 & 25,6 \\
Segundo grau incompleto & 9 & 12,7 \\
Segundo grau completo & 2 & 2,8 \\
Superior & - & - \\
Sem informacão & 2 & 2,8 \\
\hline Total & 71 & 100,0 \\
\hline
\end{tabular}

* Dados inéditos 
Tabela 2. Distribuição do $n^{2} e \%$ de trabalhadores expostos a mercúrio metálico segundo idade e presença ou ausência de intoxicaçāo. Indústria de lâmpadas elétricas no Estado de São Paulo, 1991.

\begin{tabular}{|c|c|c|c|c|c|c|c|c|}
\hline \multirow{2}{*}{\multicolumn{3}{|c|}{$\begin{array}{c}\text { Idade dos trabaihadores } \\
\text { (em anos) }\end{array}$}} & \multicolumn{2}{|c|}{ Intoxicados } & \multicolumn{2}{|c|}{ Não Intoxicados } & \multicolumn{2}{|c|}{ Total } \\
\hline & & & $\mathrm{N}^{\mathrm{Q}}$ & $\%$ & № & $\%$ & № & $\%$ \\
\hline 20 & $\vdash$ & 25 & 16 & 22,5 & 4 & 5,6 & 20 & 28,2 \\
\hline 26 & $\mapsto$ & 30 & 11 & 15,5 & 1 & 1,4 & 12 & 16,9 \\
\hline 31 & $H$ & 35 & 14 & 19,7 & 2 & 2,8 & 16 & 22,5 \\
\hline 36 & $\mapsto$ & 40 & 6 & 8,4 & - & - & 6 & 8,4 \\
\hline 41 & $\mapsto$ & 45 & 6 & 8,4 & - & - & 6 & 8,4 \\
\hline 46 & $\mapsto$ & 50 & 4 & 5,6 & 2 & 2,8 & 6 & 8,4 \\
\hline 51 & $1-1$ & 55 & 3 & 4,2 & - & - & 3 & 4,2 \\
\hline 56 & $\mapsto 1$ & 60 & - & - & 1 & 1,4 & 1 & 1,4 \\
\hline 61 & $\mapsto$ & 65 & 1 & 1,4 & - & - & 1 & 1,4 \\
\hline Total & & & 61 & 85,9 & 10 & 14,1 & 71 & 100,0 \\
\hline
\end{tabular}

Os trabalhadores estudados estavam distribuídos nas seguintes funções: mecânico de manutenção, ajudante de produção, operador de máquinas, eletricista de manutenção, lubrificador, operador de embalagem, revestidor químico, operador de empilhadeira, recuperador, inspetor de break-down, operador de materiais e faxineira (Tabela 3).

O tempo de exposiçāo variou de 4 meses a 30 anos, sendo que com tempo de exposição até 3 anos foram encontrados $34(47,9 \%)$ trabalhadores intoxicados (Tabela 4).

Os sintomas referidos foram agrupados nas síndromes gastrointestinal, neurológica, eretismo psíquico e outros sintomas. $\mathrm{Na}$ sintomatologia gastrointestinal destacam-se: a epigastralgia
$(64,8 \%)$, gosto metálico $(59,1 \%)$, digestão difícil, $(54,9 \%)$, sialorréia $(49,3 \%)$. Na sintomatologia neurológica predominam a cefaléia $(77,4 \%)$, parestesia $(57,7 \%)$, insônia $(53,5 \%)$, tremores $(49,3 \%)$. No eretismo psiquico os sintomas mais referidos foram: nervosismo $(73,2 \%)$, irritabilidade $(67,6 \%)$, distúrbios de memória $(47,9 \%)$, tristeza $(38,0 \%)$. Em outros sintomas tivemos: irritação nos olhos $(64,8 \%)$ e fraqueza muscular $(64,8 \%)$ (Tabela 5 ).

Dos sinais detectados ao exame clíniconeurológico os mais importantes na caracterização do quadro de intoxicação crônica por mercúrio foram: os tremores $(78,9 \%)$ e as alterações de cavidade oral (faringite $45,1 \%$, linha azul na margem alveolar - 21,1\%, depósi-

Tabela 3. Distribuiçăo do $n^{2}$ e \% de trabalhadores expostos a mercúrio metálico, segundo presença ou não de intoxicação e cargo/funçảo exercida. Indústria de lâmpadas elétricas, no Estado de São Paulo, em 1991

\begin{tabular}{|c|c|c|c|c|c|c|}
\hline \multirow{2}{*}{$\begin{array}{l}\text { Cargo ou Funçāo } \\
\text { Desempenhada }\end{array}$} & \multicolumn{2}{|c|}{ Intoxicados } & \multicolumn{2}{|c|}{ Não Intoxicados } & \multicolumn{2}{|c|}{ Total } \\
\hline & $N^{2}$ & $\%$ & $N^{2}$ & $\%$ & $\mathrm{~N}^{2}$ & $\%$ \\
\hline Mecânico de manutenção & 22 & 88,0 & 3 & 12,0 & 25 & 100,0 \\
\hline Ajudante de produção & 17 & 85,0 & 3 & 15,0 & 20 & 100,0 \\
\hline Operador de máquina & 13 & 100,0 & $\cdot$ & $\cdot$ & 13 & 100,0 \\
\hline Eletricista de manutenção & 2 & 50,0 & 2 & 50,0 & 4 & 100,0 \\
\hline Lubrificador & 2 & 66,6 & 1 & 33,3 & 3 & 100,0 \\
\hline Operador de embalagem & 1 & 100,0 & $\cdot$ & $\cdot$ & 1 & 100,0 \\
\hline Revestidor quimico & 1 & 100,0 & $\cdot$ & - & 1 & 100,0 \\
\hline Operador de empilhadeira & 1 & 100,0 & $\cdot$ & • & 1 & 100,0 \\
\hline Recuperador & - & - & 1 & 100,0 & 1 & 100,0 \\
\hline Inspetor de branquidāo & 1 & 100,0 & $\cdot$ & $\cdot$ & 1 & 100,0 \\
\hline Operador de materiais & 1 & 100,0 &. & - & 1 & 100,0 \\
\hline Total & 61 & 85,9 & 10 & 14,1 & 71 & 100,0 \\
\hline
\end{tabular}


Tabela 4. Distribuição do $n^{2}$ e \% de trabalhadores expostos a mercúrio metálico segundo tempo de exposição e presença ou não de intoxicação. Indústria de lâmpadas elétricas no Estado de São Paulo, 1991.

\begin{tabular}{|c|c|c|c|c|c|c|c|}
\hline \multirow{2}{*}{\multicolumn{2}{|c|}{$\begin{array}{c}\text { Tempo de Exposição } \\
\text { (em anos) }\end{array}$}} & \multicolumn{2}{|c|}{ Intoxicados } & \multicolumn{2}{|c|}{ Não Intoxicados } & \multicolumn{2}{|c|}{ Total } \\
\hline & & $\mathrm{N}^{2}$ & $\%$ & $\mathrm{~N}^{2}$ & $\%$ & № & $\%$ \\
\hline \multicolumn{2}{|c|}{ Menos de 1 ano } & 6 & 66,7 & 3 & 33,3 & 9 & 100,0 \\
\hline $1 \mapsto$ & 3 anos & 28 & 87,5 & 4 & 12,5 & 32 & 100,0 \\
\hline $4 \mapsto$ & 6 anos & 12 & 85,7 & 2 & 19,9 & 14 & 100,0 \\
\hline $7 \mapsto$ & 9 anos & 3 & 100,0 & - & - & 3 & 100,0 \\
\hline$\mapsto$ & 12 anos & 5 & 100,0 & - & - & 5 & 100,0 \\
\hline$\mapsto$ & 15 anos & 4 & 100,0 & - & - & 4 & 100,0 \\
\hline $16 \mapsto$ & 18 anos & - & - & 1 & 100,0 & 1 & 100,0 \\
\hline $19 \mapsto$ & 21 anos & 1 & 100,0 & - & - & 1 & 100,0 \\
\hline $22 \mapsto$ & 24 anos & 1 & 100,0 & - & - & 1 & 100,0 \\
\hline \multicolumn{2}{|c|}{ acima de 24 anos } & 1 & 100,0 & - & - & 1 & 100,0 \\
\hline Total & & 61 & 85,9 & 10 & 14,1 & 71 & 100,0 \\
\hline
\end{tabular}

Tabela 5. Número de trabalhadores espostos a mercúrio metálico segundo sintomatologia referida. Indústria de lâmpadas elétricas do Estado de São Paulo, 1991.

\begin{tabular}{|c|c|c|c|c|c|c|c|}
\hline \multicolumn{2}{|c|}{ Gastrointestinal } & \multicolumn{2}{|c|}{ Neurológico } & \multicolumn{2}{|c|}{ Eretismo Psiquico } & \multicolumn{2}{|l|}{ Outros } \\
\hline Sintomas Referidos & $N^{2}$ Casos & Sintomas Referidos & $N^{2}$ Casos & Sintomas Referidos & $N^{2}$ Casos & Sintomas Referidos & Ne Casos \\
\hline Epigastralgia & 46 & Cofaléia & 55 & Nervosismo & 52 & Irritaçăo nos olhos & 46 \\
\hline Gosto metálico & 42 & Parestesia & 41 & Irritabilidade & 48 & Fraqueza muscular & 46 \\
\hline Digestão diticil & 39 & Insônia & 38 & Distúrbios de memória & 34 & Borramento visual & 33 \\
\hline Sialorróia & 35 & Tremores & 35 & Tristeza & 27 & Zumbido & 29 \\
\hline Náuseas & 31 & Sonolência & 31 & Diminuiçăo da atençăo & 26 & Imritação nasal & 29 \\
\hline Cólicas intestinais & 30 & Aneraçoses de grafia & 16 & Depressáo & 25 & Dimn.acuidade visual & 26 \\
\hline Sangramento oral & 28 & Căimbras & 12 & Agressividade & 21 & Diminuiçăo audiçăo & 24 \\
\hline Gengivite & 27 & Gritos noturnos & 10 & Insegurança & 20 & Dor torácica & 23 \\
\hline Úlceraçōes orais & 26 & Diticuldade/equilibrio & 7 & Medo & 18 & Impotência sexual & 16 \\
\hline Diarréia & 25 & Abalos ínico-atoricos & 7 & Ansiedade & 18 & Disúria & 16 \\
\hline Obstipaçăo intestinal & 15 & Tontura & 4 & Vontade de morrer & 7 & Tosse & 11 \\
\hline Amolecimento/dentes & 13 & & & Perda de iniciativa & 2 & Dispnéia & 8 \\
\hline Melena & 11 & & & & & Sangramento nasal & 4 \\
\hline Hematemese & 4 & & & & & Dor muscular & 3 \\
\hline \multirow[t]{3}{*}{ Sangramento retal } & 4 & & & & & Hematúria & 2 \\
\hline & & & & & & Alteraçăo cutânea & 2 \\
\hline & & & & & & Dor de ouvido & 2 \\
\hline
\end{tabular}

tos gengivais $11,3 \%$, ulcerações orais $-8,4 \%$ ); ocorreram ainda, hipertensão arterial $(60,6 \%)$ e conjuntivite $(40,8 \%)$ (Tabela 6$)$.

Nos exames complementares efetuados, verificou-se que:

a) mercúrio urinário - 15 trabalhadores apresentaram abaixo de $10 \mathrm{mg} / 1,14$ entre $10 \mathrm{e}$ $50 \mathrm{mg} / 1,18$ acima de $50 \mathrm{mg} / 1$ e 24 sem informação;

b) elementos anormais e sedimentos urinários - houve proteinúria em 8 casos, hematúria em 2 e leucocitúria em um caso, sendo que os demais, não apresentaram alterações;

c) colesterol - os resultados foram elevados em 2 casos;

d) função hepática - transaminase glutâmica oxalacética elevada em 2 casos, transaminase glutâmica pirúvica elevada em um caso, fosfatase alcalina elevada em um caso;

e) hemograma: anemia em um, leucocitose em 16 , leucopenia em 6 , linfocitose em 6 , eosinofilia em 5 , neutrofilia em 4 , atipia linfocitária em 3;

f) função renal - uréia elevada em 4 casos e creatinina elevada em 2 .

g) eletromiografia - um caso de neuropatia periférica;

h) tomografia computadorizada cerebral - um caso de calcificação cerebral;

i) endoscopia - gastrite em 2 casos, úlcera gástrica em um e duodenal em um;

j) audiometria - 37 estavam dentro da normalidade, 20 apresentaram disacusia neurossensorial e 14 não realizaram o exame; 
Tabela 6. № $\theta \%$ de trabalhadores expostos a mercúrio metálico segundo sinais detectados ao exame clínico neurológico. Indústria de lâmpadas elétricas no Estado de Sảo Paulo, 1991

\begin{tabular}{lll}
\hline Sinais Detectados & Ne & $\%$ \\
\hline Tremores & 56 & 78,9 \\
Hipertensão arterial & 43 & 60,6 \\
Faringite & 32 & 45,1 \\
Conjuntivite & 29 & 40,8 \\
Amigdalite & 27 & 38,0 \\
Hepatomegalia & 18 & 25,3 \\
Linha azul na margem alveolar & 15 & 21,1 \\
Arritmia cardiaca & 14 & 19,7 \\
Edema de membros inferiores & 13 & 18,3 \\
Sopro sistólico de foco mitral & 12 & 16,9 \\
Depósitos gengivais & 8 & 11,3 \\
Ulceraçōes orais & 6 & 8,4 \\
Ausculta pulmonar alterada & 5 & 7,0 \\
Dor à palpação da regiāo epigástrica & 4 & 5,6 \\
Alteraçōes cutâneas & 4 & 5,6 \\
Alteraçōes de sensibilidade & 2 & 2,8 \\
Nistagno multidirecional bilateral & 1 & 1,4 \\
Espondilite anquilozante & 1 & 1,4 \\
Extração renal & 1 & 1,4 \\
Punho percussão positiva & 1 & 1,4 \\
Dentes moles & 1 & 1,4 \\
Alteração de reflexos & 1 & 1,4 \\
\hline
\end{tabular}

Os resultados dos testes neuropsicológicos realizados para verificação da memória, função motora e atenção foram:

a) memória - encontramos 55 casos $(77,5 \%)$ com distúrbios de memória variando de discretos (18 trabalhadores) a moderados ( 37 trabalhadores).

Não detectamos distúrbios graves e apenas 13 trabalhadores $(18,3 \%)$ apresentaram resultados dentro da normalidade;

b) função motora: os prejuizos mais significativos foram nos itens: recortes, pontilhagem e percussão, em que a maioria dos trabalhadores apresentou dificuldades graves.

c) atenção - em relação à rapidez de reação tivemos 43 trabalhadores com resultados deficientes $(60,6 \%)$, sendo que algumas vezes os que apresentavam pouca rapidez, mostravam melhor qualidade. Houve outros trabalhadores com grande rapidez, mas pouca qualidade. Em relação à qualidade, houve 44 trabalhadores com resultados abaixo da média (24) e abaixo do mínimo (20), ou seja, 61,9\% (Tabela 7).

O conjunto das alterações encontradas nos trabalhadores foram agrupadas tendo sido encontrados $57(80,3 \%)$ casos com alteraçōes de coordenação motora, $56(78,9 \%)$ com alterações neurológicas, $51(71,8 \%)$ com altera-

Tabela 7. Distribuição do $n^{2}$ e $\%$ dos trabalhadores expostos a mercúrio segundo resultados dos testes psicológicos. Indústria de lâmpadas elétricas no Estado de Săo Paulo, 1991.

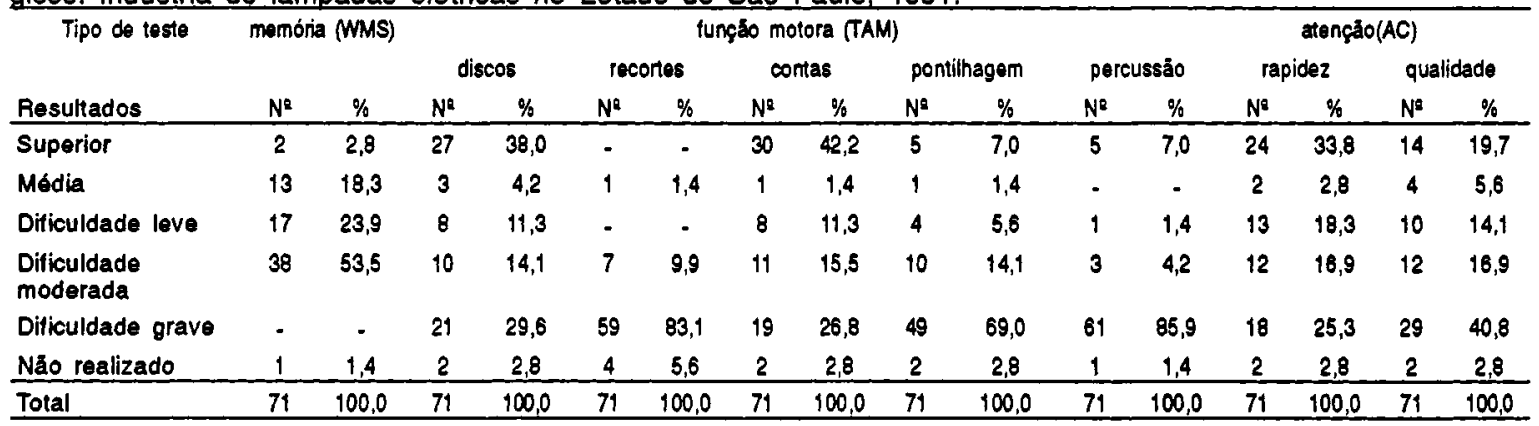

WMS - Wechsler memory scale

TAM - Teste de Aptidảo à Mecânica

AC - Atençảo concentrada

Tabela 8. Distribuição de trabalhadores espoxtos a mercúrio metálico em uma indústria de lâmpadas elétricas, segundo as alteraçōes detectadas nos exames efetuados, São Paulo, 1991.

\begin{tabular}{|c|c|c|c|c|c|c|}
\hline \multirow{2}{*}{$\begin{array}{c}\text { Trabalhadores } \\
\text { expostos } \\
\text { Alteracōes detectadas }\end{array}$} & \multicolumn{2}{|c|}{ Intoxicados } & \multicolumn{2}{|c|}{ Näo intoxicados } & \multicolumn{2}{|c|}{$\begin{array}{l}\text { Sem alteração ou } \\
\text { informação }\end{array}$} \\
\hline & $\mathrm{N}^{2}$ & $\%$ & $N^{2}$ & $\%$ & $\mathrm{~N}^{2}$ & $\%$ \\
\hline Coordenaçāo motora & 57 & 80,3 & 9 & 12,7 & 5 & 7,0 \\
\hline Neurológicas & 56 & 78,9 & 2 & 2,8 & 13 & 18,3 \\
\hline Memória & 51 & 71,8 & 4 & 5,6 & 16 & 22,5 \\
\hline Clínicas & 47 & 66,2 & 3 & 4,2 & 21 & 29,6 \\
\hline Psiquiátricas & 45 & 63,4 & 2 & 2,8 & 24 & 33,8 \\
\hline Atencảo concentrada & 37 & 52,1 & 6 & 8,4 & 28 & 39,4 \\
\hline
\end{tabular}


ções de memória, $47(7,20 \%)$ com alterações clínicas, $45(63,45 \%)$ com altetações psiquiátricas e $37(56,9 \%)$ com alterações em relação à atenção concentrada dentre os trabalhadores intoxicados (Tabela 8).

Para caracterização do quadro de intoxicação de cada trabalhador, foram levadas em consideraçāo a somatória das alterações apresentadas em cada uma das clínicas (médica, neurológica, psicológica e psiquiátrica). Em nenhum caso foi verificada alteração de apenas uma das clínicas. Em 51 (83,6\%) dos trabalhadores foram observadas alterações em, no mínimo, 3 clínicas (Tabela 9).

Tabela 9. Distribuiçăo do $n^{2}$ e \% dos trabalhadores intoxicados por mercúrio, segundo a combinação do conjunto de alteracōes apresentadas aos exames cli. nico, neurológico, psiquiátrico e psicológico. Indústria de lâmpadas elétricas, São Paulo,1991.

\begin{tabular}{lcc}
\hline Alteraçóes combinadas aos exames & \multicolumn{2}{c}{ Intoxicados } \\
& $N^{2}$ & $\%$ \\
\hline Clínico,Neurológico,Psiquiátrico,Psicológico & 34 & 55,7 \\
Clínico,Neurológico,Psicológico & 8 & 13,1 \\
Neurológico,Psiquiátrico,Psicológico & 6 & 9,8 \\
Neurológico,Psicológico & 6 & 9,8 \\
Clínico,Psiquiátrico,Psicológico & 3 & 4,3 \\
Psiquiátrico,Psicológico & 2 & 3,3 \\
Neurológico,Psicológico & 1 & 1,6 \\
Clínico,Neurológico & 1 & 1,6 \\
\hline Total & 61 & 100,0 \\
\hline
\end{tabular}

\section{4 - Conclusões}

O número de trabalhadores intoxicados foi de $61(85,9 \%)$, o que mostra a gravidade do problema, atribuido: à natureza da doença, que compromete áreas nobres do organismo; ao acometimento de trabalhadores jovens; e à ineficácia dos tratamentos existentes.

Tendo em vista a gravidade da intoxicação por mercúrio e o fato de que no ambiente de trabalho da população estudada ocorre a exposição combinada e simultânea a vários riscos, tal como na maioria dos ambientes de trabalho, consideramos que a população estudada deve ser objeto de maiores e mais aprofundadas investigações científicas. Estas devem ter como objetivos principais: o seguimento continuado e permanente desses trabalhadores, principalmente por causa da irreversibilidade dos danos apresentados em muitos casos de intoxicação mercurial; a definição de metodologias que permitam uma avaliação do peso que cada um dos riscos tem no quadro da intoxicação por mercúrio; e finalmente, e mais importante, a definição de programas mais eficazes de prevenção.

\section{Agradecimentos}

À Prof. Dr ${ }^{\mathrm{a}}$ Sabina Léa Davidson Gotlieb, da Faculdade de Saúde Pública da USP, pela leitura e comentários contribuíram para o aprimoramento do mesmo;

ao estatístico Marco Antônio Bussaco pela assessoria técnica dada;

à psiquiatra $\mathrm{Dr}^{\mathrm{a}}$ Rosita Pontes de Araújo;

à neurologista $\mathrm{Dr}^{\mathrm{a}}$ Teresa Cristina $\mathrm{M}$. Finotti pelas avaliações psiquiátrica e neurológica dos trabalhadores:

ao Dr. Luis Henrique Borges, pela elaboração do formulário de entrevista.

ZAVARIZ, C. \& GLINA, D.M.R. [Neuro-psychological clinical assessment of workers in an electric lamp factory esposed to metallic mercury]. Rev. Saúde públ., S.Paulo, 26: 356-65, 1992. This research project was undertaken for the purpose of studying poisoning by metallic mercury among workers of an electric lamp factory located in S.Paulo (Brazil). 71 workers were investigated, of whom $61(85,92 \%)$ were chronically poisoned. Exposure period ranged from 4 months to 30 years. The 57 (80.30\%) of chronically poisoned workers showed poor psychomotor co-ordination, 56 (78.88\%) showed neurological impairments, $51(71.83 \%)$ decreases in memory capacity, $47(66.20 \%)$ pathological findings in the clinical exam, $45(63.38 \%)$ psychiatric disturbances and $37(52.10 \%)$ poor performance in the concentration test.

Keywords: Mercury poisoning, epidemiology. Occupational diseases, chemically induced.

\section{Referências Bibliográficas}

1. ALONSO, F.F. Fundamentos de la psiquiatria atual. Espanha, E. Paz Mọtalvo, 1972. 2 v.

2. ANGOTZI, G. et al. Rapporti tua sposizione a mercurio e condizioni di salute in un grupo di lavoratori addetti alla distillazione di mercurio in uno stabilimento della provincia di Siena. In: Sartorelli, E. Med d. Lavoro, 71: 463-80, 1980.

3. ENCYCLOPAEDIA of Occupational Health and Safety. Geneva. International Labout Office, 1989. 2 v.

4. FOA, V. \& CAIMI, L. Patologia del mercurio e suoi composti. In: Sartorelli, E. Tratatto di medicina del. lavoro. Padova, Ed. Piccin, 1981 p. 353-76.

5. FOA, V. Neurotoxicity of elemental mercury. Occupational aspects. In: Blum, K. \& Manzo, L. Neurotoxicology. New York, Ed. Marcel Dekker Inc., 1985. p. 323-43.

6. FOA, V. \& BERTELLI G. Mercury. In: Alessio, L. et al. Biological indicators for the assessment of human exposure to industrial chemicals. Luxemburgo, Ed. Official Publications of the European Communities, 1986. p. 32-46. 
7. GALVÃO, A.C.L. \& COREY, G. Mercurio. México, Organización Panamericana de la Salud, 1987. Série Vigilância, 7

8. HANNINEN, H. Behavioral effects of occupational exposure to mercury and lead. Acta neurol. scand. Suppl., 92 (66): 167-75, 1982.

9. HARTMAN, D. Neuropsychological toxicology: identification and assessment of human neurotoxic syndromes. New York, Pergamon Press, 1988.

10. LANGOLF, G.D. et al. Evaluation of workers exposed to elemental mercury using quantitative tests of tremor and neuromuscular functions. Amer. industr. Hyg. A.ss.J., 39: 976-84, 1978.

11. OCCUPATIONAL Health Guidelines for Chemical Hazards. Washington, National Institute for Occupational Safety and Health, 1981. 2 v.

12. PIIKIVI, Lo et al. Psychological performance and long - term exposure to mercury vapors. Scand $J$. wk Environ. Hlth, 10: 35-41, 1984.
13. VROOM, F. \& GREER, M. Mercury vapour intoxication. Brain, 95: 305-12, 1972.

14. WILLIANSON, A.M. et al. Occupational mercury exposure and its consequences for behaviour. Arch. occup. environ. Hlth 50: 273-86, 1982.

15. WORLD HEALTH ORGANIZATION. Inorganic mercury. (Envirommental Health criteria 118 Geneva, 1991). 